\title{
Capital y desarrollo: \\ exposición de una relación íntima
}

\section{HENRY VELTMEYER*}

El concepto de «capital» es la clave y la piedra angular de la economía política del desarrollo y de los estudios críticos, de su discurso teórico y político. En el ensayo se exploran tres dimensiones del concepto que permiten comprender el proceso de desarrollo capitalista actual en América Latina. En el primer apartado se analiza el concepto de capital en el trabajo científico de Marx, en El capital para ser preciso; en el segundo, se expone la relación del concepto con el proceso de desarrollo en el nivel de la teoría; en el tercero se aborda tal vínculo en el contexto de la transición en el desarrollo de las fuerzas productivas en América Latina, y con respecto a las relaciones sociales y la lucha de clase correspondiente. A ese proceso se le denomina la nueva geoeconomía del capital.

\section{Marx y el capital}

El capital es la potencia económica, que lo domina todo, de la sociedad burguesa. Debe constituir el punto de partida y el punto de llegada (...) Es necesario desarrollar con exactitud el concepto de capital, ya que él mismo es el concepto básico de la economía moderna, tal como el capital mismo - cuya contrafigura abstracta es su conceptoes la base de la sociedad burguesa. De la concepción certera del supuesto fundamental de la relación, tienen que derivar todas las contradicciones de la producción burguesa, así como el límite ante el cual ella misma tiende a superarse. ${ }^{1}$

* Docente investigador en la Unidad Académica de Estudios del Desarrollo, Universidad Autónoma de Zacatecas
El proyecto de Marx consistía en estudiar el capital en cuatro libros a fin de generar una

\footnotetext{
${ }^{1}$ Karl Marx, Elementos fundamentales para la crítica de la economía política (Grundrisse), vol. I, México, Siglo XXI, 1984b [1857-1858], p. 273.
}

base científica para la política del movimiento obrero moderno. El objetivo era «llevar una ciencia, mediante la crítica, al punto en que pueda representarse dialécticamente» y, por lo tanto, «revelar la ley del movimiento de la sociedad moderna» e identificar las fuerzas generadas por el modo de producción capitalista, una combinación particular de las fuerzas productivas y las relaciones sociales correspondientes, que en algún momento se unirían para producir una forma moderna de sociedad socialista.

El capital es una crítica de la «economía política», la economía clásica de Adam Smith, David Ricardo y John Stuart Mill. Basado en la relación capital-trabajo, una relación de explotación económica, el argumento es que el capitalismo está dividido por contradicciones y fuerzas de cambio que inevitablemente llevarán a su derrocamiento, como resultado de 
acciones colectivas tomadas por la clase trabajadora una vez que ha desarrollado la conciencia de clase, es decir, que ha cobrado conciencia de su situación y de la misión histórica de crear una sociedad superior sin clases: el socialismo.

En El capital, Marx no analiza el proceso de la transformación del capitalismo en socialismo. Eso implica condiciones y fuerzas que no pueden examinarse científicamente, una lucha de clases enraizada en un sistema basado en las relaciones de producción social capitalistas. El capital es un tratado científico de las fuerzas liberadas en el proceso de desarrollo capitalista y las condiciones objetivas creadas por el funcionamiento de dichas fuerzas, condiciones que son independientes de la voluntad humana y objetivas por sus efectos en los individuos (y en los países, de acuerdo con la teoría neomarxista de la dependencia) según su ubicación en el sistema.

El primer libro es una exposición general del modo de producción capitalista, sus elementos básicos y su articulación, vistos de manera general y analítica sin considerar ciertas variables (especialmente de la circulación), sino centrándose en la fase de producción que Marx considera el fundamento de todo el sistema capitalista y de todo modo de producción. El primer tomo analiza la dinámica de la producción capitalista — el proceso de producción de capital - que depende de la conversión o transformación del dinero en capital y el producto social, así como de los medios de producción en mercancías; la producción de plusvalor, es decir, la conversión del valor de la fuerza de trabajo en salarios y ganancias; y la dinámica involucrada en la acumulación de capital.

En sentido clásico, el término de acumulación se refiere al aumento disponible no sólo de los bienes de capital propiamente dichos (maquinarias, plantas, etcétera) también de capital financiero y de capital humano (educación, capacitación, etcétera). Este aumento de capital se basa en el ahorro y la inversión productiva, proceso político del cual resulta un aumento de la riqueza de la sociedad. La riqueza creada por el capital está formada por trabajo acumulado. Materias primas, instrumentos de trabajo y medios de vida que se emplean para producir nuevas materias primas, nuevos instrumentos de trabajo y nuevos medios de vida. Sin embargo, tales elementos sólo en determinadas condiciones se convierten en capital, bajo ciertas relaciones sociales de producción.

\section{El proceso de producción capitalista}

A partir de la sección tercera del libro I, Marx se aboca a estudiar el proceso de producción capitalista. Anteriormente, había estudiado en abstracto a la sociedad mercantil, donde sólo existían productores de mercancías. Ahora estudia en abstracto a la sociedad burguesa, donde existen capitalistas y asalariados. El proceso de producción en la sociedad mercantil simple tiene un carácter dual: la producción de bienes y la producción de valor. En la sociedad capitalista el proceso de producción también ostenta un carácter dual, pero distinto al de la sociedad mercantil: es un proceso de producción de bienes y un proceso de producción de capital, de valor que se valoriza a sí mismo. Lo que distingue a la sociedad capitalista es la organización de la producción con base en el trabajo asalariado: el alquiler de la fuerza de trabajo.

La fuerza de trabajo, productora de las mercancías, se cambia, se compra y se vende como otra mercancía cualquiera; obedece a las mismas leyes del mercado, sin importar que detrás de ellas hay un hombre y su familia: el proletario. Este proletario es libre, dice Marx, parodiando el lema de la Revolución francesa, pero advierte que en realidad lo es en un doble sentido: libre (o sea carente) de medios de existencia y de medios de producción (si no vende su trabajo no sobrevive), pero libre de venderle su fuerza de trabajo al capitalista que él elija de entre los 
interesados en comprarla. El trabajador asalariado vende su capacidad para trabajar, pero ésta es inseparable de la persona y no se puede vender aisladamente; una vez hecho el contrato entre capitalista y trabajador, éste, su personalidad completa, su cuerpo entero, pasa a manos de aquel.

En los capítulos siguientes, Marx analiza las distintas formas del capital según su función en el proceso de valorización (capital constante y capital variable); el plusvalor relativo y absoluto; la jornada laboral (extensión e intensidad) y la división en trabajo necesario y plustrabajo; la tasa y la masa de plusvalor; el papel de la cooperación en el taller o la fábrica (que gracias a la optimización de la división técnica del trabajo por la manufactura resulta en una fuerza de trabajo social superior a la suma de las fuerzas de trabajo individuales); las condiciones tecnológicas en las que se realiza la producción capitalista (desde la manufactura hasta la gran industria mecanizada); la descripción $-\mathrm{y}$ denuncia - de las condiciones de vida de la clase obrera inglesa; las diversas formas de salario; por último, la acumulación del capital.

El proceso de trabajo capitalista es un proceso de valorización y de producción de plusvalor. Lo que comienza con una inversión de cierta cantidad de dinero hecha por el capitalista termina, después del ciclo, en un aumento de esa cantidad. En apariencia es como si el dinero se hubiese multiplicado por sí mismo. Marx analiza y critica las diferentes maneras en que los economistas clásicos han intentado explicar este aumento, y cómo han fracasado, pero al profundizar en la teoría del valor de $\mathrm{Da}-$ vid Ricardo, descubre el secreto de la plusvalía mientras expone el funcionamiento del modo de producción capitalista.

En el sistema capitalista la formación de la plusvalía se efectúa, de acuerdo con Marx, de la siguiente manera: el trabajador vende su fuerza de trabajo al capitalista; el capitalista se convierte en dueño de la mercancía fuerza de tra- bajo, por lo que dispone o hace uso de ella todo el tiempo que le sea posible, cada día. Como premisa, la jornada laboral se prolongará por un tiempo mayor que el necesario para producir, en las condiciones normales de trabajo, los medios de existencia y reproducción (víveres, vivienda, educación, hijos, etcétera) del obrero. A cambio, el capitalista paga al asalariado un precio por su fuerza de trabajo como lo hace por cualquier otra mercancía, es decir, paga un precio equivalente a lo que costó producirla. El capitalista no paga un precio por el trabajo que hace el asalariado, porque el precio de las mercancías no está determinado por el uso que se hace de ellas, sino por lo que costó producirlas, su valor: la cantidad de trabajo socialmente necesario invertida en producirlas.

La distinción entre fuerza de trabajo y trabajo es clave. El capitalista paga el valor de la fuerza de trabajo y a cambio recibe el valor creado por el trabajador durante la jornada laboral. De manera que en una parte de la jornada el asalariado trabaja para reproducir el valor de su fuerza de trabajo y en otra parte trabaja «gratis» para el capitalista. La diferencia entre el valor de la fuerza de trabajo y el valor acrecentado no pagado al obrero es lo que Marx denomina plusvalía, que será la base de la ganancia capitalista.

De lo anterior la premisa histórica básica es el intercambio de mercancías, pues el capitalista compra la fuerza de trabajo como una mercancía. Ello implica la otra premisa histórica básica: que las condiciones sociales son tales que el trabajador tiene que vender su fuerza de trabajo como mercancía. Marx demostró que eso es posible si el trabajador carece de medios de existencia y de medios de producción para trabajar, entonces como poseedor de sólo su fuerza de trabajo se ve obligado a venderla al capitalista para subsistir. La sociedad burguesa necesita de trabajadores libres en un doble sentido: como propietarios privados de su fuerza de trabajo y como carentes de medios de 
producción propios. El proletario está forzado a vender su capacidad de trabajo al capitalista para sobrevivir; y sólo es libre de decidir a qué capitalista se la venderá o de no venderla so pena de vivir en la marginalidad y la extrema pobreza. Los trabajadores asalariados son libres en tanto no son esclavos ni siervos: ningún poder personal los obliga a trabajar, quien lo hace es el poder impersonal de la economía.

En los siguientes capítulos, Marx expone cómo los capitalistas intentan mantener y aumentar la plusvalía. Una forma es el incremento de plusvalía absoluta mediante la extensión de la jornada laboral (incremento del tiempo en que el obrero trabaja exclusivamente para el capitalista) y la reducción del salario (parte del valor que el capitalista paga al trabajador). Pero, tal como explica Marx, existen límites «naturales» y «morales».

El capitalista procura elevar relativamente la plusvalía al modificar el proceso técnico de trabajo y las condiciones laborales, al introducir medios de producción más eficientes y al subir la intensidad del trabajo. Esto disminuye el tiempo necesario para producir las mercancías en general (donde se incluyen los medios de existencia del obrero, pues así consigue disminuir el valor de la fuerza de trabajo). Así, sin modificar la extensión de la jornada laboral, el tiempo de trabajo remunerado decrece en favor

\section{Lo que distingue a la sociedad capitalista}

es la organización de la producción

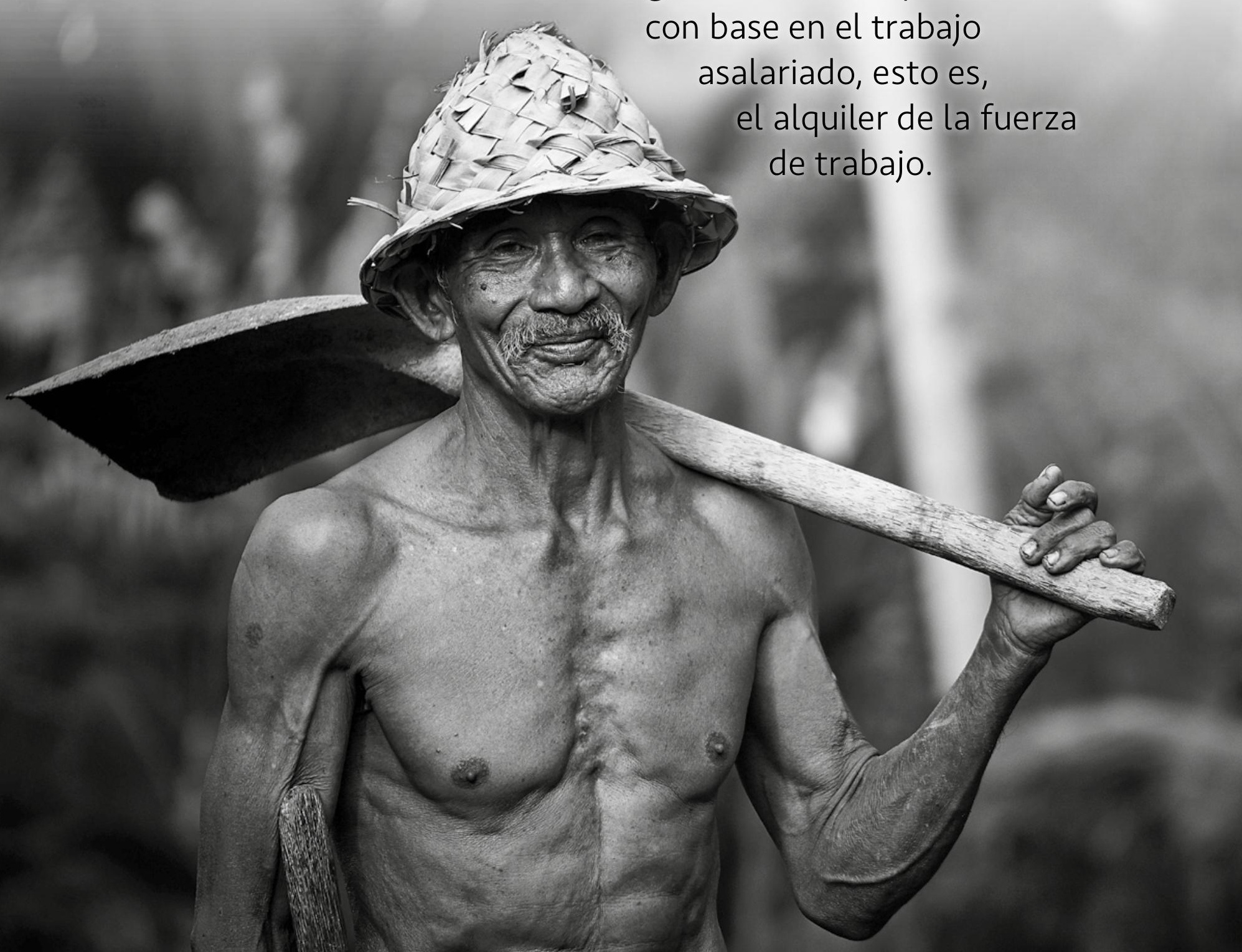


del tiempo de trabajo no remunerado, lo que Marx denomina plusvalía relativa.

Sostiene Marx que esta última consideración evidencia que, en cierto momento del desarrollo capitalista, el aumento de la plusvalía se convierte en un problema técnico. Ante los daños físicos y morales ocasionados por la larga y extenuante jornada de trabajo, la clase obrera eventualmente se organiza y consigue imponer una disminución y reglamentación de la jornada de trabajo. Si los capitalistas ya no pueden extender tal jornada, entonces el problema del incremento de la plusvalía sólo es posible de manera relativa y se torna en un problema técnico: mejorar los medios de producción. La apropiación de los inventos mecánicos ha sido el gran recurso de los capitalistas. No obstante, como argumenta Marx, eso no significa que la clase capitalista no intente quebrar la oposición de la clase obrera para extender de forma permanente la jornada de trabajo o cada vez que la plusvalía disminuya.

Marx demuestra cómo la gran industria, con la aplicación de las ciencias naturales al servicio de la mecanización del proceso de trabajo, en lugar de favorecer a la clase obrera al reducir la jornada laboral (pues lo que antes se producía en un día de trabajo artesanal ahora se efectuaba en una hora de trabajo industrial) la perjudicó de diversos modos: hacinamiento, extenuantes jornadas, trabajo infantil, insalubridad, etcétera. Esto no se debe a la industrialización, sino a su empleo capitalista.

\section{El proceso de acumulación de capital}

En la última sección del libro, que sintetiza los aportes de las secciones anteriores, Marx explica la reproducción del capital. La plusvalía extraída en la producción se convierte en ganancia, una parte de la cual es consumida por el capitalista, mientras que la otra es reinvertida en medios de producción y salarios, lo que constituye el pluscapital. El crecimiento del capital mediante la extracción de plusvalía se denomina acumulación de capital.

La ley general de la acumulación capitalista de Marx enuncia que a medida que se acumula el capital se produce y consolida un número creciente de obreros sobrantes para el sistema, denominado ejército industrial de reserva. La población supernumeraria subsiste en condiciones precarias y presiona indirectamente a la formación de condiciones de explotación mayores para los demás obreros y a la propagación de la miseria de los obreros en general. A medida que se acumula capital y por consiguiente riqueza, se produce a la par una creciente miseria en la mayoría de la población: la acumulación de capital en un polo es equivalente a la acumulación de miseria en el otro.

En el capítulo «La llamada acumulación originaria», Marx analiza cómo en Inglaterra se crearon trabajadores libres para satisfacer la demanda de fuerza de trabajo por la industria: expulsión masiva a «sangre y fuego» de los campesinos de sus tierras y una severa represión del «vagabundeo». Mediante esos métodos extraeconómicos se logró de forma acelerada una concentración de las tierras y un proletariado disciplinado para ser explotado en la industria. «Si el dinero, como afirma Augier, <viene al mundo con manchas de sangre en una mejilla>, el capital lo hace chorreando sangre y lodo, por todos los poros, desde la cabeza hasta los pies». ${ }^{2}$

«Tendencia histórica de la acumulación capitalista» es el apartado 7 del capítulo citado, desde un análisis científico e histórico retoma el programa revolucionario expuesto en el $\mathrm{Ma}$ nifiesto comunista: la expropiación de capitalistas por el pueblo y el establecimiento de una asociación de prooductores libres mediante la propiedad colectiva de la tierra y los medios sociales de producción.

${ }^{2}$ Karl Marx, El capital, tomo I, vol. III, México, Siglo XXI, 1975, p. 950. 


\section{Capital y desarrollo en el contexto actual}

El capital, en el discurso de la economía política del desarrollo, es toda forma de riqueza o recurso productivo que funciona como palanca para generar más riqueza. Así, es el factor determinante en el proceso de desarrollo de las fuerzas productivas y en el desarrollo visto como proyecto para mejorar la condición social de una población determinada. Aunque existe un consenso sobre ello, persiste una gran confusión, incluso un debate, en torno a la relación entre capital y desarrollo. La confusión se genera porque en los hechos el capital y el desarrollo adoptan distintas modalidades, pero en diversos discursos teóricos y políticos se omiten las diferencias, esto es, no se distingue el sentido en que se utiliza el concepto de capital.

Si entendemos el desarrollo de la forma en que Marx lo entendía, como la expansión de las fuerzas productivas del sistema, o co- mo lo concibieron los pioneros de la teoría del desarrollo económico (crecimiento anual del producto interno bruto), el capital relevante es distinto a aquel que se relaciona con el desarrollo comprendido como expansión plena de las capacidades de cada miembro de la sociedad, de su potencialidad humana. En ese caso, el desarrollo implica la acumulación de capital humano - conocimientos y habilidades como recurso productivo - mientras que en el caso anterior el capital aparece en forma de dinero y el desarrollo entraña la acumulación de capital en forma de capital financiero, acumulado en los mercados de capital o en el valor agregado por el trabajo como ganancias o utilidades, se retorna al dinero invertido.

Para descifrar la función del capital en el proceso de desarrollo, es necesario especificar las diversas formas que adoptan el capital y el desarrollo, y relacionarlas al marco teórico y al mundo práctico en el contexto actual. Al respecto, es pertinente el proyecto del Programa de las Naciones Unidas para el Medio

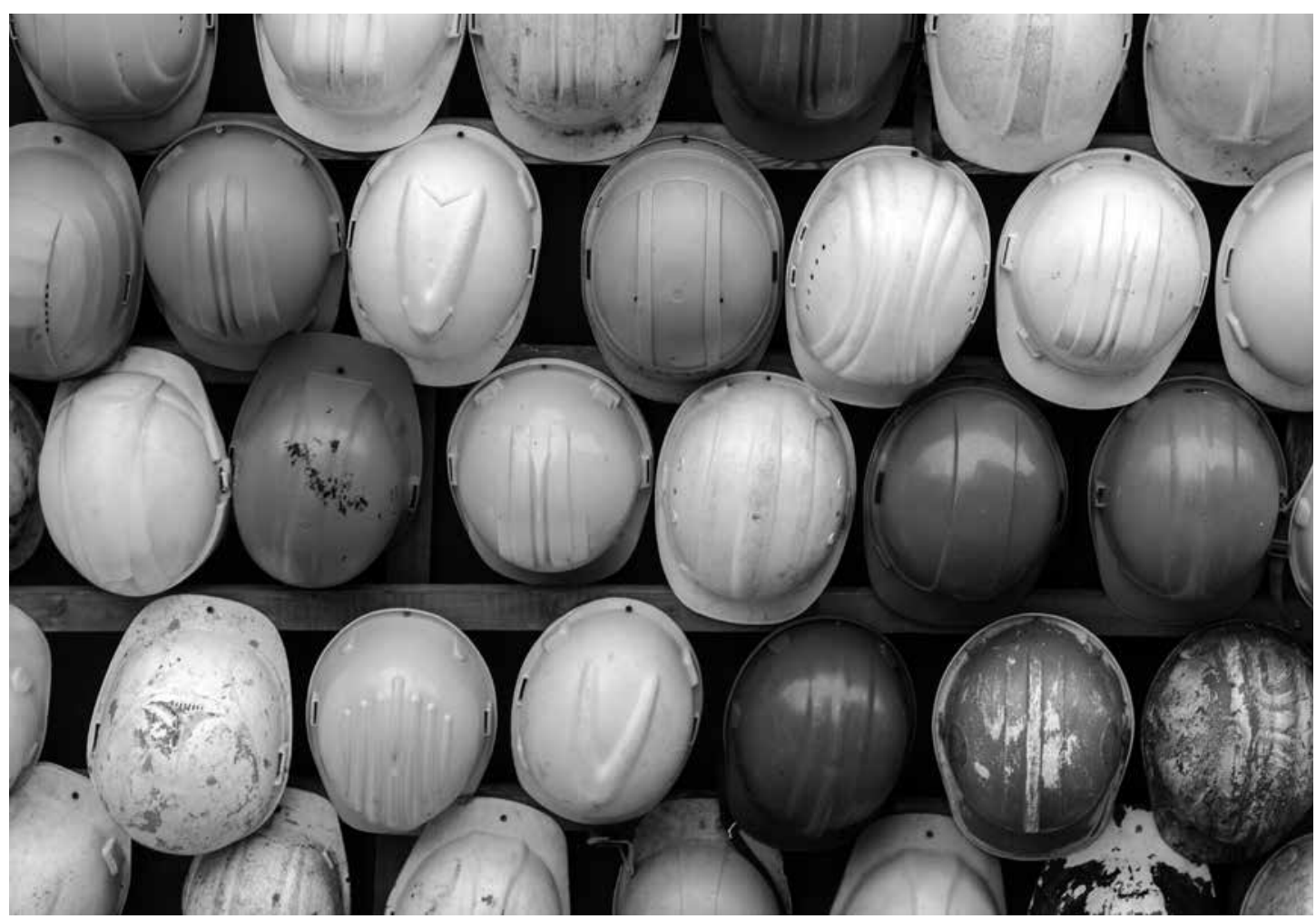

El trabajador asalariado vende su capacidad para trabajar pero ésta es inseparable de la persona y no se puede vender aisladamente. 
Ambiente (UNEP por sus siglas en inglés) y la Universidad de las Naciones Unidas/Programa Internacional de las Dimensiones Humanas del Cambio Ambiental Global (UNU-IHDP por sus siglas en inglés), publicado en 2012. Tradicionalmente, el desarrollo o el crecimiento económico se mide en términos del ingreso total de la población de acuerdo con sus actividades económicas o de la producción total de bienes y servicios, es decir, del cúmulo de mercancías (con referencia a la tendencia del capitalismo de convertir en mercancías los productos sociales y los medios de producción). En tal proceso el concepto de desarrollo se define en función del ingreso nacional: los cambios anuales en el valor total de la producción social, o el valor de los salarios totales más el valor total de la masa de capital invertido en los mercados.

Otra forma de medir el desarrollo es mediante la distribución social del ingreso nacional, en particular la participación del trabajo y el capital, o la relación entre los ingresos del trabajo dirigidos al consumo (salarios) y los ingresos del capital destinados a la inversión (capital). Pero en aquella publicación de las Naciones Unidas, por primera vez se define y mide el desarrollo nacional a partir de la riqueza total - la riqueza de las naciones, como sostenía Adam Smith — , no desde el ingreso nacional.

Conforme a este concepto de desarrollo, los economistas que suscriben la publicación de las Naciones Unidas construyeron un nuevo índice para medir la riqueza de un país - riqueza inclusiva, en su concepción - que considera, a parte del capital financiero (capital invertido en la expansión de la producción o en los mercados de capital), el capital humano (conocimientos, habilidades y sistemas de innovación, educación, potencial de percibir ingresos, expectativa de vida), el capital físico o productivo (infraestructura económica, carreteras y ferrocarriles, sistema de comunicación, vehículos y transporte, planta industrial y ma- quinaria y equipo) y el capital natural (la tierra y sus recursos: combustibles fósiles, minerales y metales, productos agrocomestibles y forestales, pesca).

En este marco teórico y conceptual, el capital y la riqueza nacional asumen cuatro formas principales: financiera, física, natural y humana. Para establecer la estructura de capital acumulado se calcula la proporción de tales formas en la riqueza nacional, lo que permite construir no sólo un ranking relativo a la riqueza total de todas las naciones en el sistema mundial (el nivel de desarrollo medido en términos de riqueza, no por los incrementos anuales en el ingreso nacional), sino la proporcionalidad y función de estas formas de capital o recursos productivos.

Un análisis comparativo de la riqueza de las naciones elaborado por los autores del Informe de riqueza inclusiva 2012, descubrió que en las naciones más desarrolladas el capital humano configura una alta proporción de la riqueza nacional: 90 por ciento en Reino Unido y 78 por ciento en Estados Unidos. Mientras que en los países relativamente menos desarrollados, como los de América Latina, destaca el capital natural -30 por ciento en el caso de Chile y 46-47 por ciento en Colombia y Venezuela. ${ }^{3}$

Naciones como Japón, un país «desarrollado» o avanzado debido a su riqueza y desarrollo, poseen un capital natural (valor de los recursos naturales extraídos y convertidos en mercancías) con una participación menor, sólo 1 por ciento. ${ }^{4}$ En la estructura de la riqueza de estos países, destaca la acumulación de capital humano (73 por ciento en Japón) y el capital físico (26 por ciento en Japón). Los datos del informe refuerzan la teoría de la maldición de

\footnotetext{
${ }^{3}$ United Nations University-International Human Dimensions Programme on Global Environmental Change and United Nations Environment Programme (UNU-IHDP/UNEP), Inclusive Wealth Report 2012. Measuring progress toward sustainability, Cambridge, Cambridge University Press, 2012. ${ }^{4}$ UNU-IHDP/UNEP, op cit.
} 
recursos ${ }^{5}$ - la idea de que los países más ricos en recursos naturales suelen ser relativamente pobres en cuanto a su riqueza nacional.

Al efectuar la contabilidad de la riqueza nacional por país y un análisis comparativo de la base productiva de la economía por la composición del capital, se obtuvieron los siguientes datos. El factor predominante en el proceso de acumulación y desarrollo en las naciones ricas es el capital humano. En Estados Unidos hasta 78 por ciento del stock de capital acumulado en el periodo de 1990 a 2008 era capital humano versus 16 por ciento para capital productivo y 7 por ciento de capital natural. ${ }^{6}$ Referente a otros países desarrollados (Japón, Reino Unido, Alemania, Francia), el peso de capital humano en la riqueza nacional total varía de 67 a 90 por ciento. En comparación, el peso del capital producido oscila entre 9 (Reino Unido) y 26 por ciento (Japón). Respecto al peso del capital natural en la riqueza nacional, fluctúan entre 1 por ciento (Japón, Reino Unido, Francia) y 8 por ciento (Alemania).

Para los países que experimentaron un proceso de industrialización rápido en décadas recientes - China, India-; el capital humano fue un factor importante, pero lo que destaca es la acumulación de capital producido o físico. En estas naciones el capital manufacturado o producido en el periodo 1990-2008 experimentó una expansión desproporcionada —-168 por ciento en caso de India - ; por su parte, el capital humano aumentó a una tasa más baja, mientras que el capital natural disminuyó. Sin embargo, aun en estos países el capital humano fue el factor principal en el proceso de desarrollo.

En la riqueza nacional de los tres países citados, el peso del capital producido fue aproximadamente de 17 por ciento en comparación con la participación de los capitales humano y natural, un promedio de 37 y 46 por ciento, res-

${ }^{5}$ Richard M. Auty, Sustaining development in mineral economies: the resource curse thesis, London, Routledge, 1993.

${ }^{6}$ UNU-IHDP/UNEP, op. cit. pectivamente. Esto implica que, si bien fueron testigos de los mayores incrementos en el capital producido, la contribución al índice de riqueza inclusiva es el más bajo en los países de referencia. ${ }^{7}$

Pero éstos son sólo ejemplos circunscritos a la esfera nacional. Hace falta analizar las dinámicas de la acumulación, las formas en que se ha movilizado y acumulado el capital en la producción de la riqueza nacional a escala del sistema mundial. Es evidente que en la mayoría de los casos el principal motor del crecimiento económico y la expansión de la riqueza nacional han sido los capitales humano y productivo. Sin embargo, debe considerarse el contexto. Por ejemplo, en las condiciones actuales de la nueva geoeconomía del capital en América Latina (véase el siguente apartado) es posible detectar una expansión relativa de capital extractivo (a partir de la acumulación de capital en su forma natural) y, por lo tanto, una expansión de su función en el proceso de desarrollo. El Informe de riqueza inclusiva 2012 establece que el capital humano, el conocimiento como recurso productivo, es el mecanismo principal de acumulación, factor determinante en el proceso de desarrollo económico.

\section{La nueva geoeconomía del capital en América Latina}

Con la promoción del Consenso de Washington en los 1980 que estipulaba un capitalismo de libre mercado y destrabar las «fuerzas de libertad económica» (capital, mercado, empresa privada) de la regulación restrictiva del Estado de desarrollo y de bienestar, el proceso de desarrollo capitalista experimentó una involución y una transformación de gran alcance en la periferia del sistema mundial de capital. En América Latina hubo una gran afluencia de capital en forma de multinacionales e inversión

${ }^{7}$ Idem. 
Cuadro 1. Distribución porcentual de IED por sector en América Latina

\begin{tabular}{lccccccccc} 
& 2000 & 2001 & 2002 & 2003 & 2004 & 2005 & 2006 & 2007 & 2008 \\
\hline Recursos & 10 & 12 & 12 & 11 & 12 & 13 & 12 & 15 & 30 \\
Fabricación & 25 & 26 & 38 & 35 & 38 & 37 & 36 & 35 & 22 \\
Servicios & 60 & 61 & 51 & 48 & 46 & 48 & 51 & 49 & 47 \\
\hline
\end{tabular}

Fuente: Adaptado de J.M. Arellano, «Canadian Foreign Direct Investment in Latin America», Background Paper, North-South Institute, Ottawa, 2010, tabla 2.

extranjera directa (IED). Para 1990, la región se convirtió en destino y receptáculo de una oleada de capitales que buscaban mercados y sectores rentables para la inversión productiva o fuentes de trabajo barato, oportunidades económicas y ganancias extraordinarias vinculadas con la extracción, mercantilización y exportación de recursos naturales.

El cuadro 1 expone una panorámica general de los flujos de capital y las dinámicas de acumulación, lo cual puede denominarse como «la nueva geoeconomía del capital» en la región. En este marco, se advierte el predominio del capital en la búsqueda de recursos y un flujo creciente a la periferia sudamericana, donde una variedad de condiciones conspiró para favorecer el resurgimiento del capital extractivo, entre ellas el auge de los productos básicos y una serie de gobiernos obedientes y ansiosos por aprovechar su ventaja comparativa en recursos naturales. Varios cambios en la economía global, especialmente el ascenso de China como potencia económica y la expansión de la demanda de recursos naturales, incitaron ese proceso, lo que resultó en una «nueva dependencia».8

En el contexto latinoamericano, la nueva dependencia se ha conformado como la explotación de los recursos naturales y la exportación de bienes primarios - hidrocarburos, metales y

\footnotetext{
${ }^{8}$ Atilio Borón, «Teorías de la dependencia», Realidad Económica, núm. 238, agosto-septiembre 2008; Carlos Eduardo Martins, Globalizacao, dependencia e neoliberalismo na América Latina, Sao Paulo, Boitempo, 2011; Adrián Sotelo, «Neoimperialismo, dependencia e novas periferias», en A América Latina e os desafíos da globalizaca, Rio de Janeiro, Boitempo, 2009.
}

minerales, agroalimentos, productos forestales, biocombustibles - a gran escala. ${ }^{9}$ Los proyectos extractivos generalmente implican inversiones a gran escala (a menudo extranjeras) en el acaparamiento de tierras: ${ }^{10}$ concesiones para explorar y extraer minerales y metales, infraestructura para proyectos de desarrollo emprendidos por empresas transnacionales y actividades de capital intensivo que generan poco empleo más allá de la etapa de construcción. El extractivismo en ese contexto también requiere una expansión territorial constante - la extensión de la frontera extractiva a áreas remotas donde aún quedan grandes reservas de minerales, fuentes de energía y productos agroalimentarios sin explotar-, que conduce al desplazamiento o la destrucción de formas alternativas de producción local y formas de vida. Para Svampa y otros académicos latinoamericanos centrados en el extractivismo, ${ }^{11}$ el resultado es la proliferación

\footnotetext{
${ }^{9}$ Maristella Svampa, «Resource extractivism and alternatives: Latin American perspectives on development», Journal für Entwicklungspolitik (JEP), vol. 28, núm. 3, 2012, pp. 43-73; Maristella Svampa y Enrique Viale, Maldesarrollo. La Argentina del extractivismo y el despojo, Buenos Aires, Katz, 2014. ${ }^{10}$ Saturnino Borras, Jennifer Franco, Sergio Gómez, Cristobal Kay y Max Spoor, «Land grabbing in Latin America and the Caribbean», Journal of Peasant Studies, vol. 39, núms. 3-4, 2012, pp. 845-872.

${ }^{11}$ Eduardo Gudynas, «The new extractivism in South America: ten urgent theses about extractivism in relation to current South American progressivism», Bank Information Center, 2010, in http://www.bicusa.org/en/Article.11769.aspx; Eduardo Gudynas, «La izquierda de los límites al nuevo extractivismo», La Primera, 2011, en http://www.diariolaprimeraperu. com/online/columnistas/la-izquierda-de-los-limites-alnuevo-extractivismo_85841.html; Eduardo Gudynas, «Extractivisms: concepts, local impacts and spill-effects», in Ronaldo Munck and Henry Veltmeyer (eds.), Alternative development models: Latin American results and prospects?,
} 
